\title{
VIOLENCIA POLÍTICA EN LA PROVINCIA DE LLANQUIHUE DURANTE LA REFORMA AGRARIA DE LA UNIDAD POPULAR, 1970- $1973^{*}$
}

\author{
POLITICAL VIOLENCE IN THE PROVINCE OF LLANQUIHUE DURING \\ THE UNIDAD POPULAR'S AGRARIAN REFORM, 1970-1973
}

\author{
FELIPE SÁNCHEZ B. ${ }^{* *}$
}

RESUMEN: El artículo describe y examina la violencia rural asociada con la implementación de la Reforma Agraria en la provincia de Llanquihue durante la Unidad Popular (UP), y los límites que enfrentó el gobierno para manejar esta situación. Se analiza uno de los casos más dramáticos y desconocidos de este periodo, como fue la balacera ocurrida en el fundo "Mirador" cerca de Frutillar, donde un grupo de agricultores y miembros de "Patria y Libertad" asesinaron a tres campesinos. A pesar de que el gobierno intervino en estos hechos, nadie sería declarado culpable, debido al acceso privilegiado de los agricultores a la Justicia formal. Estos hechos ocurrirían en un contexto de progresiva radicalización social y política en el país, mientras que a nivel local sería la tardía aparición de grupos especialistas en violencia, lo que explicaría este dramático caso.

Palabras Clave: Chile, violencia política, Reforma Agraria, Unidad Popular, provincia de Llanquihue.

AbSTRACT: This article describes and examines the rural violence associated with the Unidad Popular's (UP) implementation of the Agrarian Reform in the province of Llanquihue, as well as the limits faced by the government in dealing with the situation. The analysis focuses on one of the most dramatic yet unknown cases from the period: the shooting death of three peasants in the "Mirador" ranch near the town of Frutillar, which was carried out by a group of landowners and members of Patria y Libertad. Despite the government's involvement in the aftermath, nobody was found guilty due to the landowners' privileged access to the justice system. While these events occurred within the context of the country's progressive social and political radicalization, the

\footnotetext{
* Este artículo es parte del trabajo desarrollado en la tesis de Magíster en Historia finalizado en 2014 en la Pontificia Universidad Católica de Chile (PUC). Agradezco a Conicyt por su Beca Magíster Nacional, y al Centro de Estudios de Conflicto y Cohesión Social (COES, FONDAP 15130009), que patrocinó esta tesis.

** Magíster en Historia. Estudiante de Doctorado en Sociología PUC. Becario Conicyt Doctorado Nacional. Correo electrónico: fasanchez@uc.cl.
} 
relatively late appearance at the local level of groups specializing in the use of violence helps to explain this dramatic episode.

Keywords: Chile, political violence, Agrarian Reform, Unidad Popular, Province of Llanquihue.

Recibido: Aceptado: 26.01.17. Aprobado: 17.05.17.

\section{INTRODUCCIÓN}

T a Reforma Agraria chilena fue la mayor distribución de tierras agrícolas hacia sectores campesinos implementada por el Estado, sin una revolución agraria violenta que la antecediera (Tinsman, 2009, pp. 9-10). Su carácter institucional permitió la desmantelación del latifundio en un espacio de tiempo considerablemente breve y de manera más bien pacífica. Con todo, la violencia en los campos no fue un elemento ausente durante este proceso. En provincias como Cautín o Valdivia donde la radicalización de las reivindicaciones territoriales mapuche, la presencia activa de grupos de extrema izquierda como el $\mathrm{MCR}^{1}$, así como de propietarios agrícolas dispuestos a armarse y "tomar la justicia por sus propias manos", la violencia política alcanzó niveles dramáticos (Mallon, 2004, pp. 98-99). No obstante, comparada con estas provincias sureñas, en Llanquihue se observó una menor recurrencia de hechos violentos durante este periodo. Lo anterior llama particularmente la atención, considerando que esta provincia experimentó una movilización campesina de similar envergadura a las de Cautín o Valdivia. En todo caso, de los pocos episodios violentos ocurridos en Llanquihue, la mayoría fueron llevados a cabo por sectores opositores altamente radicalizados, y cuyas consecuencias trascenderían el espacio local, contribuyendo así a encender aún más el enfrentamiento político a nivel nacional.

Precisamente, el objetivo de este artículo es describir y analizar uno de los casos más trágicos y desconocidos de violencia rural durante este periodo ocurridos en esta provincia, y que tendría como escenario un fundo cerca de la comuna de Frutillar, en donde algunos propietarios agrícolas junto a miembros de "Patria y Libertad" asesinaron a tres campesinos, dejando heridos a otros seis. A pesar de estos hechos, la Justicia no condenaría a nadie, profundizando los resentimientos y odiosidades entre campesinos

\footnotetext{
${ }^{1}$ Movimiento Campesino Revolucionario. Brazo "rural" del Movimiento de Izquierda Revolucionaria (MIR).
} 
y propietarios agrícolas. Como se verá más adelante, el uso de la violencia por parte de los propietarios estaría cruzado por la constante tensión entre la incapacidad de contener la movilización rural, y la posibilidad de llevar a cabo acciones fuera de la legalidad sin mayores repercusiones judiciales, gracias a su posición ventajosa frente al sistema de justicia.

\section{VIOLENCIA POLÍTICA DURANTE LA UNIDAD POPULAR}

Comparada con la violenta represión llevada a cabo por el Estado con posterioridad al Golpe Militar, la violencia política durante el gobierno de Allende fue mínima. A pesar de ello, serían los grupos opositores los que se encargarían de crear una "atmósfera de violencia" en el país, la cual utilizarían, en última instancia, como argumento para justificar la intervención militar de 1973 (Stern, 2009). Paradójicamente, los hechos de violencia política más notables habían sido ejecutados por sectores vinculados a la derecha. En 1967, en pleno gobierno de Eduardo Frei, fue asesinado el funcionario de la Corporación de Reforma Agraria (CORA) Hernán Mery, en un confuso incidente, que involucró a un terrateniente, y que sería explicado por la derecha como una consecuencia natural de la implementación de una Reforma Agraria con sentido político, persecutoria y de amedrentamiento (Valdivia, 2008, p. 249). Asimismo, en 1970, con el objeto de evitar que el Congreso confirmara la presidencia de Salvador Allende, un grupo de civiles apoyados económicamente por la CIA, asesinarían al General René Schneider, en un intento de crear un ambiente de caos y miedo. El incidente sólo provocaría el efecto contrario, abriendo un espacio de negociación entre la izquierda y la Democracia Cristiana (DC), permitiendo a Allende llegar a La Moneda.

Por su parte, la izquierda se mantuvo en una constante indecisión respecto de las estrategias en su avance hacia el socialismo. Si bien Allende estaba convencido de permanecer dentro de los marcos de la legalidad, tuvo una actitud bastante condescendiente con grupos que, como el MIR o ciertos sectores del Partido Socialista (PS), creían que era necesario acelerar el proceso revolucionario a través de la acción directa, argumentando la imposibilidad de construir el socialismo por medio de la institucionalidad burguesa. Con todo, la mística guerrillera no pasó de ser una actitud y un discurso, junto a una escasa preparación militar y una, aún más, escasa cantidad de armas (Fermandois, 2013, p. 479; Valdivia, 2003, p. 185). Además, la "acción directa" no necesariamente significó la utilización de la violencia 
física. La participación de estos grupos se basó en la organización de pobres urbanos y campesinos para llevar a cabo las "tomas" -de sitios y fundos, respectivamente- con el fin de acelerar el proceso revolucionario. Ninguno de los dos tipos de ocupaciones implicaba violencia directa sobre terceros: mientras las "tomas de sitio" consistían en ocupaciones de pedazos de tierras vacíos, ubicados generalmente en sectores marginales de la ciudad, las "tomas de fundos" no eran más que el bloqueo de la entrada a la propiedad y, eventualmente, la paralización de las faenas agrícolas. Sin embargo, fueron este tipo de acciones las que la derecha utilizó para proyectar una imagen de violencia revolucionaria, responsabilizando directamente a la Unidad Popular (Winn, 2010, p. 246).

En este sentido, los campos del sur de Chile pasaron a ser un escenario destacado en el desplazamiento de la política hacia formas más extremas. En provincias como Cautín o Valdivia, con una alta densidad mapuche, que vieron el proceso de Reforma Agraria como una oportunidad para logar sus reivindicaciones territoriales, las "tomas" desbordaron la vida política del espacio local. Además, la activa participación que tuvo el MCR en esta zona fue utilizada por los sectores opositores para estimular la idea de una "conspiración mirista" que operaba en la zona y utilizaba a los mapuche para llevar a cabo sus objetivos (Mallon, 2004, p. 94). La construcción de esta imagen de violencia, caos e ilegalidad, les otorgaría a los agricultores locales la justificación que legitimaría la reacción que, en muchos casos, efectivamente fue violenta.

Los trabajos dedicados al estudio de este periodo en la zona de la Araucanía han coincidido en la rapidez con la que los terratenientes reaccionaron una vez que la UP asumió el gobierno, desplegando una actitud de amenaza y amedrentamiento que se combinaría con el uso generalizado de armas de fuego (Correa, Molina y Yáñez, 2005, p. 176; Mallon, 2004, p. 13). Por ejemplo, en la "retoma" del fundo Rucalán, liderada por su dueño, Juan Landerretche, el tiroteo que se produjo solo dejó un herido de gravedad: Ricardo Mora Carrillo, el líder de la "toma" (Mallon, 2004, pp. 94-101). Por su parte, el trabajo de Correa et al. (2005) también confirmaría la reacción amenazante y violenta de los terratenientes, al relatar la "retoma" del fundo "Huilo" en Lautaro, donde el propietario junto a familiares y amigos, ingresarían al predio disparando en contra de los ocupantes -una comunidad mapuche-, dando muerte a los hermanos Francisco y Segundo Cheuquelen (Poder Campesino, $1^{\text {a }}$ quincena de septiembre de 1971, pp. 4-5).

El único agricultor que murió en estos enfrentamientos fue Rolando 
Matus Castillo, quien, apoyando una "retoma" en Pucón, fue alcanzado por una bala en medio de un intercambio de disparos con miembros del MCR en abril de 1971. Sin embargo, a pesar de que hubo heridos en ambos bandos, este hecho confirmó la tesis esgrimida desde la derecha de un "clima de violencia" causado exclusivamente por la presencia de "miristas", quienes entrenaban a campesinos y mapuches en supuestos campamentos guerrilleros, que nunca fueron comprobados (El Llanquihue, 27 de febrero de 1971, p. 9). Asimismo, la muerte de este agricultor reforzaría aún más la solidaridad entre los propietarios agrícolas y otros grupos opositores, dando paso a la creación del "Comando Rolando Matus", organizado exclusivamente para la confrontación violenta.

La temprana y radical reacción que se observa en los propietarios agrícolas entre las provincias de Cautín y Valdivia parece estar relacionada con la masiva movilización rural y la presencia efectiva del MCR, la cual fue utilizada por la oposición para persuadir a la población de que la violencia revolucionaria era una amenaza inminente (Winn, 2010, p. 247). Tanto el nuevo y agitado contexto político producido por la llegada de la UP, así como la amplia distancia social y política entre los actores en esta zona, rápidamente polarizó la situación, desplazando la política hacia formas más extremas. Contrariamente, en la provincia de Llanquihue, a pesar de haber experimentado un aumento en la movilización campesina similar a estas otras provincias sureñas (ver Cuadro 1), la violencia rural no solo fue tardía, sino que cuantitativamente menor. Ahora bien, es preciso aclarar que a diferencia de las otras provincias referidas, la movilización rural en Llanquihue fue liderada por la DC, la cual, a pesar de su rol de agitador, seguía siendo un opositor moderado. Lo anterior, sumado a la ausencia de un conflicto mapuche significativo y una menor actividad del MCR, permitió un acercamiento entre los actores, conteniendo el conflicto político al menos en esta primera etapa.

CuAdro 1. Número de fundos ocupados en el sur de Chile, 1968-1971.

\begin{tabular}{lcccc}
\hline Provincia & 1968 & 1969 & 1970 & 1971 \\
\hline Cautín & 1 & 2 & 54 & 112 \\
Valdivia & 3 & 81 & 31 & 158 \\
Osorno & 2 & 4 & 41 & 66 \\
Llanquihue & 1 & 1 & 52 & 134 \\
\hline
\end{tabular}

Fuente: Klein (1972). 
Con todo, los episodios de violencia en Llanquihue, aunque tardíos, no fueron inexistentes ni menos extremos en su desarrollo y consecuencias. Los casos de violencia más relevantes fueron protagonizados por sectores opositores a la UP, en específico, propietarios agrícolas. Estos episodios estuvieron profundamente trazados por un contexto nacional cada vez más polarizado, dada la emergencia de grupos especializados en acciones violentas, así como por un acceso preferente de los agricultores locales a la Justicia, la que les ofreció garantías para llevar a cabo acciones de violencia como parte de su lucha contrarrevolucionaria, gozando de una amplia impunidad.

\section{LA APARICIÓN DE GRUPOS ESPECIALISTAS EN VIOLENCIA EN LA PROVINCIA DE LLANQUIHUE}

Uno de los aspectos más significativos que marcó el ascenso de la UP fue el creciente protagonismo que comenzaron a tener grupos extremistas - de izquierda y derecha- en el panorama político. Si bien el MIR -el más importante de estos grupos en este periodo- había iniciado sus operaciones en la década de 1960, la llegada al poder de una coalición política liderada por la izquierda ofreció un contexto propicio para aumentar sus actividades y expandirse por el territorio nacional. En respuesta, sectores de una derecha nacionalista y antiliberal fundarían "Patria y Libertad" (PyL) a fines de 1970; y en abril de 1971 se formaría el "Comando Rolando Matus" (CRM), emulando así a las Brigadas "Ramona Parra" y "Elmo Catalán" de los partidos Comunista y Socialista, respectivamente. En el sur, estos grupos tendrían especial protagonismo a partir de los violentos sucesos ocurridos en la Araucanía. Su presencia en esta zona respondió a un contexto local de rápida polarización y cuya principal característica sería la oportunidad que las comunidades mapuche, con históricas reivindicaciones territoriales, encontrarían en este nuevo escenario político.

En la provincia de Llanquihue, estas organizaciones llegarían recién a inicios de 1972, en un periodo marcado por la consolidación del bloque político opositor PN-DC, la intensificación del proceso revolucionario "desde abajo" y la incapacidad de la UP de contener este proceso, debido a las propias divisiones internas (Valenzuela,1989, pp. 163-165). El "Comando Rolando Matus" junto a "Patria y Libertad" serían los principales agentes encargados de llevar a cabo acciones de violencia o de cooperar en ellas. En tal sentido, a pesar de los pocos episodios de violencia registrados, su 
principal característica no fue la espontaneidad o descoordinación, sino su alto grado de organización y la coherencia en los objetivos buscados. Por lo mismo, sus consecuencias políticas y sociales traspasaron los márgenes estrictamente locales, para poner a Llanquihue en el centro del debate político nacional.

\section{POLARIZACIÓN Y VIOLENCIA POLÍTICA EN EL SECTOR AGRÍCOLA}

A partir de 1972, el campo sería el principal escenario de los episodios de violencia ocurridos en esta provincia. En enero de 1972, El Llanquihue denunciaba un "grave ataque y amenazas a dirigentes de la Federación de Sindicatos de Empleadores Agrícolas (FESIEMA) en ocupación de un campo" (El Llanquihue, 20 de enero de 1972, p. 5). Según el diario, el Gobernador de Puerto Varas, junto a dirigentes de FESIEMA habían sido interceptados "por un grupo de 30 a 40 ocupantes ilegales que les impidieron su intervención en el problema" de la "toma" del fundo "Colegual" de Heinz Hortsmann. Además, el mismo periódico informó que dicho campo había sido ocupado por personas ajenas al predio y que, entre otros perjuicios ocasionados, se habían beneficiado de una vaquilla de dos años:

en un atropello total a la propiedad privada sin que el Gobernador actuara para imponer el respeto a la autoridad (...) mientras los dirigentes de Fesiema recibían los más graves insultos y amenazas con palos y herramientas de labranzas (...) e inclusive varios de los ocupantes portaban armas de fuego bajo sus vestimentas (El Llanquihue, 20 de enero de 1972, p. 5).

Las reacciones ante tal denuncia no se harían esperar. Sería el propio Gobernador quien rechazaría en cada una de sus partes la acusación realizada por FESIEMA. La autoridad departamental indicaría que efectivamente llegó con el presidente de la organización patronal, Augusto Minte, hasta el fundo "Colegual", acompañado además por Jorge Olate Aranzabe, Inspector del Trabajo de Puerto Varas. En dicha visita pudieron comprobar que el campo había sido tomado por los propios obreros que ahí trabajaban, apoyados por el sindicato "Chile Nuevo". Entre las demandas de los ocupantes se encontraba la solución al problema de sus casas "que dicho sea de paso, se encuentran en pésimas condiciones, indignas de albergar a seres humanos" (El Porteño, 19 de febrero de 1972, p. 13). Sin embargo, 
la principal preocupación de los obreros había sido "la amenaza, revólver en mano, hacia José Sánchez, dirigente sindical, por parte del señor Horstmann, cuando llegó hasta su casa para solicitarle la firma de un formulario que debía presentar en una oficina pública" (p. 13). Junto con lo anterior, el Gobernador calificó de tendenciosa y falsa la información entregada por Minte a El Llanquihue respecto del porte de armas por parte de los ocupantes, ya que la supuesta carabina que el dirigente patronal había denunciado estaba en poder de los campesinos no era sino un "pedazo de madera al cual se le agregó una cañería de cobre y esa es el arma que al señor Minte le hizo temblar los pantalones" (p. 13). Finalmente, la autoridad explicaba que la información entregada por Minte fue:

producto de una acalorada discusión que sostuvimos en la Gobernación cuando se trataba de solucionar la huelga campesina que paralizó los fundos (...) boicoteando la producción para que el gobierno no pueda cumplir con el programa de entregar a cada niño medio litro de leche. Fue ahí donde Minte, en presencia de dirigentes sindicales y de la Unidad Popular, indignado expresó que jamás perdonaría al Gobernador porque no se le había aceptado su proposición sino la petición hecha por el sindicato Arturo Prat; y [...] con la prepotencia que le es habitual, entregara informaciones que no se ajustan a la realidad (p. 13).

¿Quién poseía las armas? ¿Qué tan acalorada fue la discusión? Lo cierto es que la imposibilidad de detener las "tomas" de predios agrícolas en la provincia estaba comenzando a desesperar a los propietarios. En marzo de 1972 fueron tomados dos fundos en la comuna de Los Muermos por razones laborales; en Llanquihue el fundo "Las Encinas" había sido tomado por miembros de los sindicatos "Eduardo Frei” y "Salomón Corvalán”, mientras en el campo de Felmer Niklitschek en Puerto Varas, se denunciaba que los ocupantes impedían la cosecha de pasto, fundamental para alimentar al ganado. Estas eran solo algunas de las "tomas" a las que se sumaban otras que se arrastraban incluso desde finales de 1970 (El Llanquihue, 12 de marzo de 1972, p. 5; y 22 de marzo de 1972, p. 4).

Esta situación mantenía profundamente preocupadas a las autoridades locales que, a través de la presión ejercida por los propietarios agrícolas, buscaban solucionar cuanto antes el problema de las "tomas". En mayo de 1972, el diputado del Partido Nacional (PN), Evaldo Klein, solicitó una reunión con Salvador Allende para exponerle "el serio problema de esta provincia donde continúan las ocupaciones ilegales de predios agrícolas. Se toman los campos expropiados por CORA sin esperar que sean entre- 
gados, y siguen tomados los predios no expropiados" (El Llanquihue, 3 de mayo de 1972, p. 7). Más trágico era el balance que hacía Mario Marchant Binder, regidor de Puerto Montt, quien sostenía que "mientras se toman los predios ilegalmente y se cometen toda clase de tropelías desde amenazas e insultos hasta robo y abigeato que mantienen una activa campaña del terror a quienes producen, la justicia no se hace presente" (El Llanquihue, 11 de junio de 1972, p. 7).

La imposibilidad de detener las "tomas" de fundos iba provocando profunda impotencia entre los agricultores que, tal como reflejó el incidente entre el gobernador de Puerto Varas y el presidente de FESIEMA, estaba llevando incluso a sus propios dirigentes a verse envueltos en episodios sumamente delicados. En marzo de 1972, la situación en el fundo "El Toro", ubicado en Fresia, se volvía cada vez más tensa entre propietarios y ocupantes. Luisa Carrillo, esposa del propietario, había denunciado un atentado a bala supuestamente realizado por los ocupantes, junto al interventor de CORA, José Lira. Por su parte, días después, los obreros que se habían "tomado" este campo hicieron una denuncia similar en contra de los hijos de los propietarios, quienes habrían interceptado a José Lira acompañado de un dirigente sindical, cerrándoles el paso con un tractor y amenazándolos con un rifle y un revólver. Según indicó una declaración del PS local, de no haber sido por la intervención de Luisa Carrillo "se habría producido un hecho lamentable, aunque ella también profería amenazas" (El Porteño, 31 de marzo de 1972, p. 10).

Más allá de la exactitud de los hechos denunciados, lo cierto es que el conflicto rural en la provincia estaba avanzando hacia una confrontación cada vez más agresiva. La progresiva distancia entre agricultores y obreros rurales comenzaba a expresarse ya no tanto en declaraciones públicas sino más bien en acciones directas que no solo bordeaban la legalidad. Estas acciones, como se verá a continuación, se tornarían abiertamente violentas, en la medida en que ciertos factores, como un sistema de justicia favorable a los agricultores y la participación de grupos especialistas en violencia entre otros elementos- facilitaron que este tipo extremo de acción política emergiera en la provincia.

\section{LA BALACERA EN EL FUNDO “MIRADOR” Y LOS LÍMITES DE LA JUSTICIA FORMAL}

El máximo despliegue de violencia política en la provincia de Llanquihue 
ocurrió en un asentamiento campesino en Frutillar, y sus protagonistas serían un grupo de agricultores locales, y un grupo de miembros de PyL. El enfrentamiento dejó tres campesinos muertos y ningún condenado. A pesar de que sería el único incidente donde se llegaría a tal grado de violencia durante este periodo en la provincia, dejó profundas consecuencias sociales y políticas a nivel local y nacional. Asimismo, estos dramáticos sucesos terminarían por develar los límites que el proyecto de vía chilena al socialismo no pudo superar, al no ser capaz el gobierno de la UP de llevar a ningún responsable a la Justicia y, en consecuencia, dejar en evidencia su incapacidad de proteger efectivamente a los grupos populares que su proyecto buscaba representar.

La reconstrucción de los hechos es la siguiente: la tarde del 23 de agosto de 1972, el funcionario de CORFO, Alberto Hechenleitner, había organizado una reunión en el fundo "El Mirador" en la comuna de Frutillar para finiquitar una venta de ganado con el ex dueño de aquel predio, Helmuth Daetz. Este último iba acompañado de Gastón Domínguez -amigo de Daetz y abogado de la Asociación de Agricultores de Llanquihue (Agrollanquihue)- y Violo Catalán, empleado de Daetz. Una vez realizadas las diligencias, el funcionario junto a Daetz, Domínguez y Catalán procedieron a abandonar el fundo, pero un grupo de al menos 20 miembros del asentamiento "Diego Portales" que funcionaba desde hacía un mes en dicho campo, solo permitió la salida de Hechenleitner. Según los asentados, no permitieron la salida del propietario porque este estaba llevándose maquinarias de la lechería y una bomba elevadora de agua que los campesinos reclamaban como parte del inventario del asentamiento. En tales circunstancias, el ex propietario y sus acompañantes se quedaron en la casa de Roberto Cárcamo, ex trabajador de Daetz que aún vivía en la misma propiedad. Ahí se habrían quedado aproximadamente hasta las cinco y media de la mañana del jueves 24 , cuando rompieron la cadena que impedía la salida del campo, logrando salir de este en sus vehículos personales además de un tractor que se encontraba en el mismo predio. Sin embargo, en el camino vecinal serían interceptados por los miembros del asentamiento "Balmaceda" que cruzaba dicho camino. Ahí encontrarían el único acceso a la carretera bloqueado con troncos. Estos serían removidos por Catalán con el tractor que había extraído desde "El Mirador". Al intentar escapar fueron atacados con palos por los asentados que se encontraban bloqueando el paso. En ese momento apareció un grupo de agricultores del sector, acompañado de otro grupo de personas identificadas como miembros de PyL. Todos iban armados y procedieron a disparar una cantidad indetermi- 
nada de balas, dando muerte inmediata a Luis Rivas González de 16 años. Quedarían gravemente heridos, falleciendo posteriormente en el hospital de Osorno, el padre de Luis Rivas, Juan Rivas Rivas de 46 años, y Roberto Almonacid Ascencio de 54 años. Además de las víctimas fatales, otros seis campesinos quedarían con heridas de diversa gravedad como consecuencia de la balacera (El Llanquihue, 26 de agosto de 1972, p. 7; El Surazo, primera quincena de septiembre de 1972, pp. 8-9; Poder Campesino, septiembre de 1972, p. 3; El Porteño, del 1 al 15 de septiembre de 1972, pp. 3-6; y Punto Final, 12 de septiembre de 1972, pp. 2-5).

Las declaraciones efectuadas por los involucrados en el momento posterior al incidente tuvieron, como era de esperar, varias contradicciones. La más significativa de ellas correspondió, sin duda, a la disputa respecto de si los hechos habían sido planificados con anterioridad, o si fue un incidente fortuito con resultados no esperados por parte de los acusados. Según las declaraciones de los campesinos, Daetz y Domínguez habrían elaborado el ataque armado mientras se encontraban refugiados en la casa de Roberto Cárcamo. Desde ahí habrían coordinado con los demás agricultores y el grupo de apoyo de PyL el escape y el uso de las armas de fuego. Según Ernesto Gatica, dirigente del asentamiento "Diego Portales", los propietarios agrícolas "portaban todos armas de fuego... Hornick [uno de los agricultores involucrados] andaba con metralleta y así otros con revólveres... iban con gorros pasamontañas, con cascos protectores... así que venían bien equipados, venían a hacer lo que hicieron" (Poder Campesino, septiembre de 1972, p. 6). Para Gatica no había duda que Daetz y los demás agricultores habían llegado hasta el asentamiento con la intención de dispararle a los campesinos: "no fue un enfrentamiento este, sino una masacre porque ellos iban pasando aquí y ametrallaron todo y ni una piedra se les tiró a los vehículos" (Poder Campesino, septiembre de 1972, p. 6). El Porteño agregaba que "los vehículos ya en la vía pública y al pasar al frente a los 12 campesinos indefensos, los mandamases, Daetz y Domínguez, ordenaron a sus fieles acompañantes disparar" (El Porteño, 15 de septiembre de 1972, p. 3), reforzando así la noción de un crimen cuidadosamente meditado.

Establecer el grado de organización previa y la intencionalidad premeditada de los disparos no era una discusión menor. No solo estaba en juego la penalidad de los hechos, sino, y más importante, era confirmar la existencia de grupos de extrema derecha compuestos principalmente por agricultores locales, armados y dispuestos a organizar ataques en contra de trabajadores y cualquiera que se opusiera a sus intereses. Por su parte, los principales acusados -Daetz y Domínguez- negarían cualquier tipo de or- 
ganización y premeditación en los hechos. Además, descartaron totalmente que el ataque haya sido sin mediar provocación. Los acusados insistieron en que al momento de intentar escapar sus vehículos fueron atacados con palos, piedras y herramientas de trabajo pero que, a pesar de lo anterior, no solo no habían disparado ni una bala en contra de los campesinos, sino que ni siquiera conocían a quienes dispararon. El Llanquihue informó que, según la investigación en proceso, los inculpados habrían declarado que "los disparos fueron efectuados por unos desconocidos que se habían subido a la parte trasera de la camioneta de Daetz y que más o menos a las 5 horas, había llegado hasta donde estaban ellos, en casa de Cárcamo, a ofrecerle ayuda desinteresadamente para ayudarles a salir del fundo" (El Llanquihue, 26 de septiembre de 1972, p. 7). Con estas declaraciones, los agricultores acusados buscaban darle un carácter mucho más fortuito a los hechos. Ellos no eran asesinos, ni estaban armados, y no tenían ningún vínculo con aquel grupo que les ofreció ayuda "desinteresadamente".

Cuarenta años después, Gastón Domínguez, uno de los principales involucrados en estos hechos, entrega una visión distinta a la recogida en las fuentes consultadas. Domínguez recordaba que a eso de las cinco de la mañana había llegado "un amigo" hasta la casa de Roberto Cárcamo a auxiliarlos con una barretilla, con la cual pudieron romper los alambres que les impedían la salida del fundo. Al llegar hasta el camino público, el acceso que daba hacia la carretera se encontraba bloqueado con troncos, pero:

llegó un equipo de amigos... estábamos más o menos organizados. Y en un momento le disparan un balazo y le da en un brazo a un campesino que se llamaba Cheyo Sáez (...). Después de eso se produjo una paralojización de toda la gente. Todos quedaron convertidos en momias. Y yo reaccioné: ¡Qué estamos esperando! Le dije yo ¡Saca esos troncos Violo [Catalán]! Y con el tractor sacó los troncos y quedó la pasada, y con el camioncito de Helmuth, se abrió calle. Yo pasé detrás en el auto mío. Y venía un camión. Allí venían como catorce amigos nuestros. Y éstos dispararon como si hubiesen sido salvas de dieciocho de septiembre. (Sánchez, F. Entrevista a Domínguez, 17 de octubre de 2012).

Ahora es el propio Domínguez quien confirma la hipótesis de que efectivamente se habían organizado con otros agricultores para escapar del fundo (hipótesis que habían negado durante la investigación). Aún más, el grupo de apoyo llegó hasta ese lugar disparando a mansalva, según el relato antes citado. "Como si hubiesen sido salvas de dieciocho de septiembre", señala Domínguez. La afirmación anterior llama profundamente la aten- 
ción, considerando lo que parece una clara desproporción entre el ataque armado realizado por los agricultores y sus "amigos", y el ataque con palos y herramientas que los obreros habrían realizado en contra del propietario y sus acompañantes.
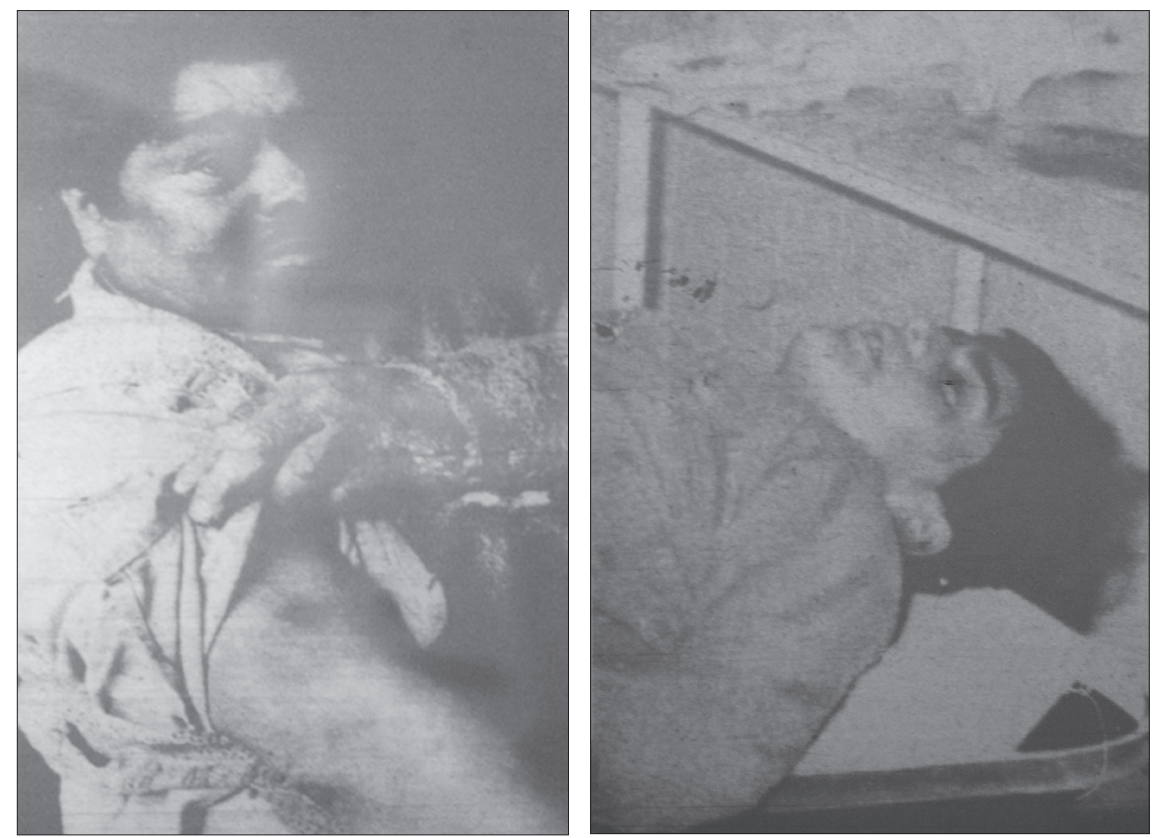

Eusebio "Cheyo" Sáez muestra el brazo donde le impactó la bala que, según el relato de Domínguez, fue debido a que Sáez lo estaba amenazando con un arma. Al lado, Luis Rivas, el joven obrero de 16 años víctima de la balacera. Fuente: Poder Campesino, agosto 1972.

Ahora bien, respecto de la militancia política de quienes participaron en este incidente, Gastón Domínguez negó que él y los demás agricultores involucrados hayan pertenecido a PyL o al CRM, pero sí confirmó que todos ellos eran militantes del P. Nacional. Además, también afirmó que él tenía protección de PyL debido a las constantes amenazas que recibía como defensor de los propietarios agrícolas locales. Pero también porque tanto por su rol de abogado como por su propio compromiso político, significó que se haya visto involucrado en situaciones bastantes conflictivas y confusas.

Éramos todos del Partido Nacional, pero nosotros no éramos guerrilleros (...). Nosotros teníamos un grupo de amigos que fueron convo- 
cados cuando surgió esta situación. A mí "Patria y Libertad" me puso un par de guardaespaldas, porque yo estuve en varios baleos. Yo para irme a Puerto Varas ya tenía que cambiar de auto a mitad de camino. Estábamos en plena guerra (Sánchez, F. Entrevista a Domínguez, 17 de octubre de 2012).

A pesar de negar ser miembro de PyL, el relato no solo confirma la presencia de este grupo en la provincia, sino también que esta organización consideraba a Domínguez un elemento bastante valioso como para entregarle protección personal. Esto último hace pensar en la existencia de una organización de carácter más permanente, con capacidad de conseguir armas y movilizar rápidamente gente dispuesta a utilizar estas armas. En tales circunstancias, es muy probable que los propios guardaespaldas que PyL le designó a Domínguez hayan portado armas no solo con una finalidad defensiva. Si en la memoria de este abogado, el tiempo de la Reforma Agraria era de verdadera guerra, el uso de armas en contra de obreros rurales parece que se legitima por sí mismo. Al menos en el incidente del fundo "Mirador" da la impresión de haber sido así. Cuando se le preguntó a Domínguez su opinión respecto del actuar que tuvo él y sus aliados en estos hechos, el abogado respondió: "Nosotros actuamos en defensa propia. Nosotros fuimos los interferidos. No al revés" (Sánchez, F. Entrevista a Domínguez, 17 de octubre de 2012).

\section{EL ACCESO PRIVILEGIADO A LA JUSTICIA}

La gran conmoción que provocaron estos hechos hizo que el Ministro del Interior, Jaime Suárez, y la Ministra del Trabajo, Mirella Baltra, viajasen hasta Puerto Montt donde se realizaron los funerales de los obreros victimados. En dicha oportunidad, la Ministra Baltra señalaría que "el presidente Allende fue conmovido profundamente ante el asesinato de estos campesinos en cobarde acción de la derecha y la reacción" (El Llanquihue, 28 de agosto de 1972, p. 2). En la misma alocución y luego de dar las respectivas

condolencias a los familiares informaría que "El Gobierno, sin embargo, ha tomado todas las medidas para que sientan los culpables todo el peso de la Ley y no queden sus crímenes impunes" (p. 2). Similares declaraciones serían las expresadas por el Ministro Suárez, cuando señaló que "no hemos venido sólo a expresar un sentimiento de condolencias. Fundamentalmente nuestra presencia quiere ser una manifestación de la voluntad inexorable del gobierno para que se haga justicia” (p. 2). Sin embargo, la voluntad del 
gobierno por buscar justicia solo quedó en estas declaraciones. El proceso judicial sería criticado por una serie de procedimientos denunciados como irregulares.

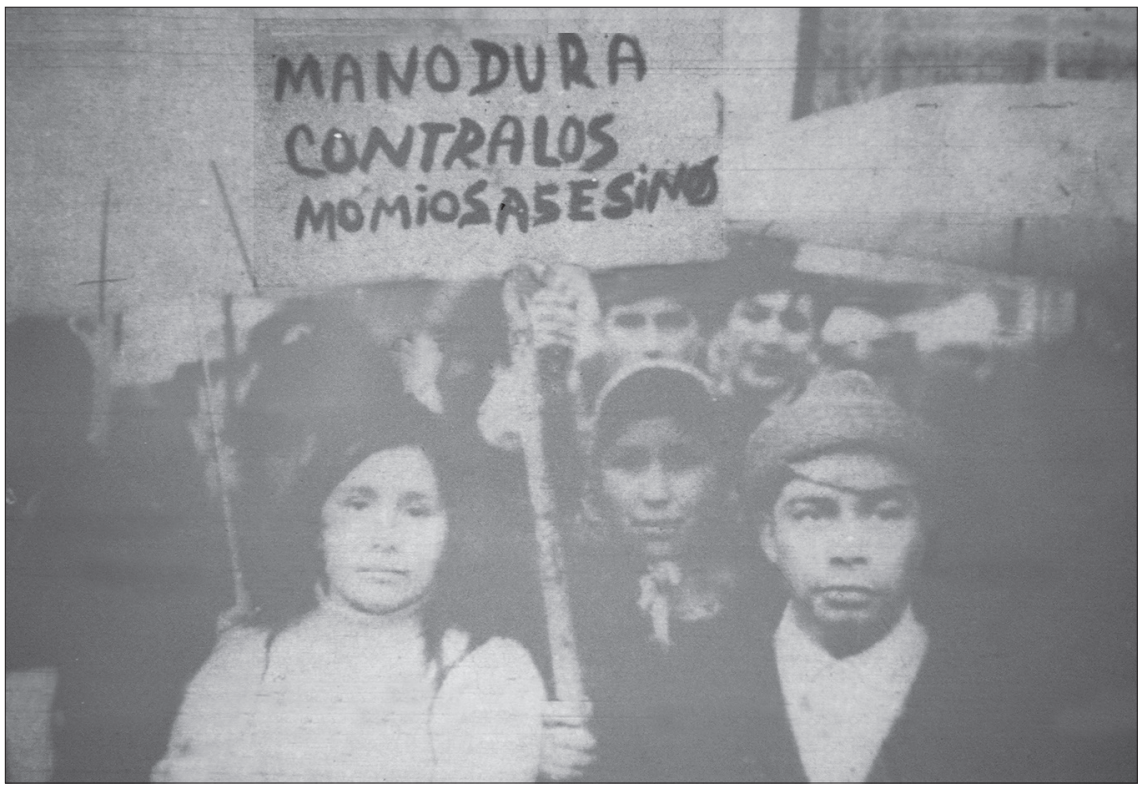

Campesinos de Frutillar pidiendo justicia para sus compañeros del fundo "Mirador". Fuente: Revolución Agraria, agosto 1972.

En la primera audiencia realizada en el Juzgado del Crimen de Puerto Varas se denunció que, a pesar de haber una orden de incomunicación para los doce agricultores que fueron formalizados, estos habían sido vistos en los pasillos de dicho tribunal conversando libremente con sus familiares (Punto Final, 12 de septiembre de 1972, p. 2; El Surazo, primera quincena de septiembre de 1972 , p. 8). Junto con lo anterior, el recién nombrado intendente de la provincia, Óscar Ramos, denunció la necesidad de nombrar un Ministro en Visita encargado de llevar a cabo la investigación del caso, debido a "irregularidades e infidencias en el proceso". Se trata de un proceso muy delicado y sabemos que hay infidencias de funcionarios [del Juzgado de Puerto Varas]" (El Llanquihue, 29 de agosto de 1972, p. 7). Serían estas denuncias, junto a la gravedad de los hechos a investigar, lo que motivaría el traslado del caso a la Corte de Apelaciones de Valdivia.

El Ministro en Visita sería Hilario Ruiz, quien llevó adelante la investigación por medio de la Policía de Investigaciones. Entre los procedimientos 


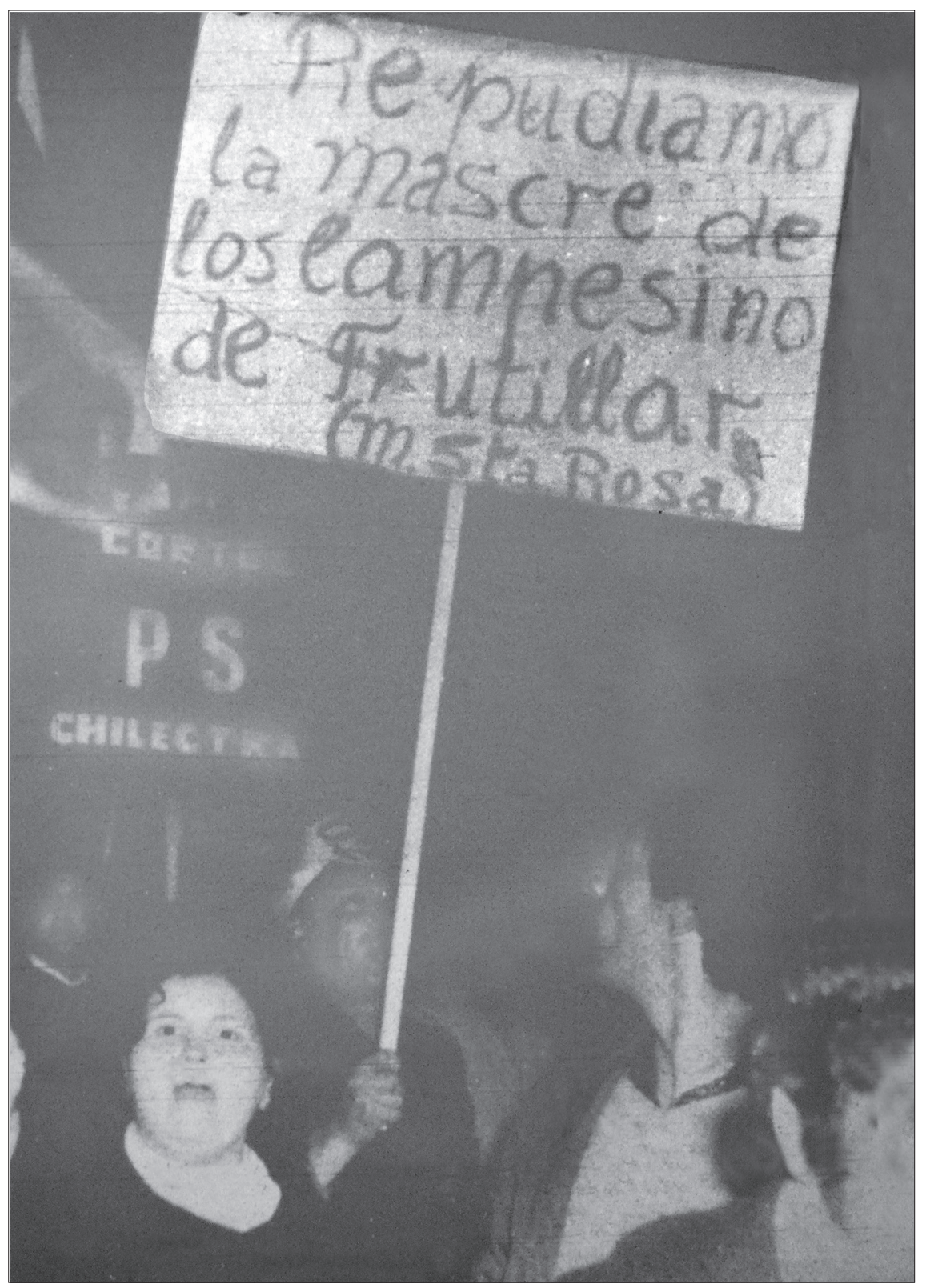

Trabajadores en Santiago manifestando su rechazo a los hechos ocurridos en el sur. Fuente: Poder Campesino, agosto 1972. 
ordenados por Ruiz estuvo el allanamiento de los domicilios de los doce acusados. Durante la diligencia se encontró una gran cantidad de armas y municiones, las cuales fueron enviadas a Santiago para los peritajes balísticos correspondientes (El Llanquihue, 9 de septiembre de 1972, p. 7). El proceso se extendería alrededor de dos meses, en los cuales no se pudo establecer ninguna responsabilidad penal. Gastón Domínguez recordaría que:

El caso fue sobreseído porque se determinó que las muertes se habían producido en riña o pelea. La riña o pelea es una circunstancia que permite disminuir la penalidad, y esto pasa porque cuando hay riña o pelea no se sabe quién pegó a quién o quién disparó. No se trataba de un homicidio simple, que es lo que sucede si yo efectivamente te disparo. Sino que fue una reyerta, una pelea. Y en esa pelea, claro, se disparó y se produjo la muerte de algunos (Sánchez, F. Entrevista a Domínguez, 17 de octubre 2012).

El acceso privilegiado a la Justicia permitiría a los propietarios agrícolas escapar de cualquier tipo de responsabilidad en la muerte de los tres campesinos. Más aún, el argumento de la "riña o pelea", al implicar la imposibilidad de determinar desde dónde provinieron los disparos, puso a los obreros rurales como eventuales ejecutores de sus propios compañeros: "Establecieron lo que se les antojó -señalaría Eusebio "Cheyo" Sáez, uno de los campesinos heridos en el incidente- (...) que los campesinos se habían matado entre sí y que el asesinato de tres trabajadores y las heridas de otros cinco eran producto de una pelea entre hermanos de clase" (Poder Campesino, septiembre de 1972, p. 16). Los propietarios agrícolas, por su parte, fueron defendidos por un grupo de varios abogados, comenzando por el propio Domínguez: "Yo hice las defensas desde dentro. Nosotros fuimos defendidos por mi papá, Eugenio Fernández, Alberto Ebensperger y los alegatos los pronunció Alfonso Podlech ${ }^{2}$ Él hizo los alegatos finales por los cuales obtuvimos la libertad provisional. Eso fue en octubre en 1972" (Domínguez, 17 de octubre de 2012). Las redes de solidaridad establecidas entre los propietarios agrícolas se activarían para protegerse mutuamente y proteger sus intereses. No solo fueron defendidos por un amplio equipo de

\footnotetext{
${ }^{2}$ Podlech no solo sería un activo defensor de los propietarios agrícolas en Temuco, sino que, como Fiscal Militar durante la dictadura, estaría implicado en varios casos de torturas, desapariciones y muerte de varios militantes del Partido Comunista y algunos ciudadanos ítalo-chilenos, como el sacerdote Omar Venturelli.
} 
abogados ligados por lazos de parentesco y amistad, sino que tanto Agrollanquihue como la Sociedad Agrícola y Ganadera de Osorno (SAGO) asumieron el pago de los honorarios del abogado Podlech (Agrollanquihue, 26 de octubre 1972). Si bien varios de los acusados -comenzando por Gastón Domínguez- pertenecían a estas instituciones, las acciones que derivaron en la muerte de estos campesinos no parecen haber estado dentro de los acuerdos oficiales tomados por estos gremios patronales.

\section{LÍMITES Y OBSTÁCULOS DEL PROYECTO DE VÍA CHILENA. COMENTARIOS FINALES}

La implementación de la Reforma Agraria acabó para siempre con el latifundio, base del Sistema de Hacienda, el cual había definido la vida social, política y económica en Chile durante tres siglos. Así, la Reforma se constituyó como un proceso de reestructuración social profundo e irreversible. Evidentemente, esta situación impuso importantes desafíos al proyecto de vía chilena al socialismo que el gobierno de Allende intentaba llevar a cabo, y del cual la Reforma Agraria era un pilar fundamental. Uno de los obstáculos más difíciles que debió enfrentar la UP se derivó de su pretensión de transformar la totalidad de las relaciones sociales dominantes de la época, sobre la base de una institucionalidad concebida para mantener y reproducir dichas relaciones históricas de dominación. Las leyes y la justicia, como arenas en disputa durante este periodo (Aguirre y Salvatore, 2001), demostraron ser un espacio absolutamente dominado por los sectores opositores, no tanto porque la justicia haya tomado conscientemente una postura política en la coyuntura específica -aunque efectivamente así fue (Amunátegui, 2011; Hilbink, 2007)- sino porque históricamente el aparataje institucional del sistema judicial fue estructurado para proteger ciertos privilegios fundamentales en el orden social que el proyecto de vía chilena buscaba revolucionar.

Los vertiginosos acontecimientos que ocurrieron obligaron a los representantes del Poder Judicial a establecer claramente los marcos desde los cuales operaría su función de impartir justicia. Esta toma de posición favorecería a los agricultores locales, quienes encontraron amplias garantías en la legislación vigente. Mientras el gobierno y toda la izquierda buscaron insistentemente darle un carácter político a los incidentes en Frutillar, los propietarios agrícolas lograron demostrar que la muerte de los campesinos en el fundo "Mirador" se debió a una simple pelea, pudiendo desdramatizar 
los hechos para su propia conveniencia. En tal sentido, a pesar del desbordamiento de la movilización rural en Llanquihue, su acceso privilegiado a la Justicia les permitió explorar formas más extremas de política contenciosa sin el riesgo de tener que enfrentar a esa misma Justicia.

Ahora bien, optar por el uso de la violencia como forma de acción política también estuvo trazado por aspectos contingentes. Uno de ellos fue la emergencia de grupos especializados en violencia. Charles Tilly (2003) ha mostrado cómo la existencia de estos grupos, en contextos específicos, puede determinar que un episodio de contienda política relativamente pacífico -como una protesta pública- pueda volverse violento, ya que son estos grupos los que generan, promueven y coordinan diferentes tipos de acciones violentas, siendo también los encargados de definir los objetivos de tales acciones. Además, como grupos especializados, usualmente son capaces de calcular qué lugares y momentos, y qué tipo de acciones conviene ejecutar.

Así, fue el desenvolvimiento particular de la contienda política en la provincia de Llanquihue lo que dio paso a que este tipo de acciones tuvieran un espacio en el cual desarrollarse. Las acciones de violencia política en la zona -al menos las registradas- fueron bastante menores en términos cuantitativos comparadas con otras provincias del sur del país. Esto se pudo haber debido a la existencia de posturas menos radicales, tanto de los propietarios agrícolas, como de los propios campesinos. En efecto, más allá de la gran cantidad de "tomas" que se registraron en el periodo, las exigencias desde las cuales surgían este tipo de acciones fueron mayormente demandas salariales, sociales o de tipo laboral, las cuales podían fácilmente ser negociadas entre las partes. En cambio, en provincias como Cautín o Valdivia, la movilización liderada por comunidades mapuche tenía un carácter reivindicativo sobre los territorios considerados como usurpados. Así, junto con el apoyo de grupos radicales como el MCR, no dejaba espacio para ningún tipo de negociación, lo que contribuyó a polarizar las posturas y avanzar directamente en acciones extremas. En cualquier caso, los propietarios agrícolas demostrarían una formidable capacidad en el despliegue de recursos y en el establecimiento de alianzas para combatir políticamente a los campesinos movilizados, a la Reforma Agraria y a la Unidad Popular.

\section{REFERENCIAS}

Agrollanquihue (octubre de 1972). Acta de las Sesiones del Directorio de Agrollanquihue, Puerto Montt.

Aguirre, C. y Salvatore, R. D. (2001). Introduction: Writing the History of Law, 
Crime, and Punishment in Latin America. In R. Salvatore \& G. Joseph (Eds.), Crime and Punishment in Latin America Law and Society since Late Colonial Times (pp. 1-33). Durham and London: Duke University Press.

Amunátegui, A. (2011). El protagonismo político del Poder Judicial entre los años 1965 y 1973. Revista de Derecho de la Pontifica Universidad Católica de Valparaíso, (36), 619-663.

¡Así actuaron los fascistas! (15 de septiembre de 1972). El Porteño, pp. 3-6.

Campamentos guerrilleros funcionarían en esta región. (27 de febrero de 1971). El Llanquihue, p. 9.

Correa, M., Molina, R. y Yáñez, N. (2005). La Reforma Agraria y las tierras mapuches. Chile 1962-1975. Santiago: Lom.

Culminó trabajo policial en caso Asentamiento Balmaceda. (9 de septiembre de 1972). El Llanquihue, p. 7.

Dos campesinos asesinados en la lucha por la tierra. (primera quincena de septiembre de 1971). Poder Campesino, pp. 4-5.

El Crimen de los Latifundistas. (septiembre de 1972). Poder Campesino, p. 3.

En estado de tensión mantienen a modestos campesinos de "El Toro." (31 de marzo de 1972). El Porteño, p. 10.

Fermandois, J. (2013). La Revolución Inconclusa. La izquierda chilena y el gobierno de la Unidad Popular. Santiago: Centro de Estudios Públicos.

Gobernador aclara un hecho distorsionado. (19 de febrero de 1972). El Porteño, p. 13.

Grave ataque y amenazas a dirigentes de FESIEMA en ocupación de un campo. (20 de enero de 1972). El Llanquihue, p. 5.

Hilbink, L. (2007). Judges beyond Politics in Democracy and Dictatorship: Lessons from Chile. Cambridge: Cambridge University Press.

Intendencia denuncia irregularidad en proceso por sucesos de "Mirador" (29 de agosto de 1972). El Llanquihue, p. 7.

Klein, E. (1972). Antecedentes para el estudio de conflictos colectivos en el campo, 1967-1971. Santiago: ICIRA, mimeografiado.

La agricultura enfrentada a la quiebra en esta provincia. (11 de junio de 1972). El Llanquihue, p. 7.

La Burguesía en Armas. (12 de septiembre de 1972). Punto Final, pp. 2-5.

Latifundistas actuaron en Comandos Paramilitares en Masacre en Frutillar. (primera quincena de septiembre de 1972). El Surazo, pp. 8-9.

Los campesinos de Frutillar exigen sanción para asesinos de sus compañeros. (septiembre de 1972). Poder Campesino, p. 16.

Mallon, F. (2004). La sangre del copihue. La comunidad de Nicolás Ailío y el Estado chileno, 1906-2001. Santiago: Lom.

Ocupantes ilegales impiden cosecha de pasto en un fundo. (22 de marzo de 1972). El Llanquihue, p. 4.

Sepultados ayer en Puerto Montt campesinos muertos en Frutillar. (28 de agosto de 1972). El Llanquihue, p. 2. 
Se tomaron un fundo en comuna de Los Muermos. (12 de marzo de 1972). El Llanquihue, p. 5.

Stern, S. (2009). Recordando el Chile de Pinochet. En vísperas de Londres 1998. Santiago: Ediciones Universidad Diego Portales.

Testimonios de la masacre. (septiembre de 1972). Poder Campesino, p. 6.

Tilly, C. (2003). The Politics of Collective Violence. Cambridge: Cambridge University Press.

Tinsman, H. (2009). La tierra para el que la trabaja. Género, Sexualidad y movimientos campesinos en la Reforma Agraria chilena. Santiago: Lom/Centro de Investigaciones Barros Arana.

Tomas ilegales de predios agrícolas grave problema. (3 de mayo de 1972). El Llanquihue, p. 7.

Valdivia, V. (2003). Terrorism and Political Violence during the Pinochet Years: Chile, 1973-1989. Radical History Review, 85, 182-190.

Valdivia, V. (2008). Nacionales y gremialistas: el "parto" de la nueva derecha política chilena, 1964-1973. Santiago: Lom.

Valenzuela, A. (1989). El quiebre de la democracia en Chile. Santiago: FLACSO.

Versión oficial del incidente frente al asentamiento Balmaceda. (26 de agosto de 1972). El Llanquihue, p. 7.

Winn, P. (2010). The Furies of the Andes. Violence and Terror in the Chilean Revolution and Counterrevolution. En: Greg Grandin and Gilbert Joseph (eds.), A Century of Revolution. Insurgent and Counterinsurgent during Latin America's Long Cold War (pp. 239-275). Durham and London: Duke University Press. 